\title{
Cauda Equine Syndrome due to Dislocated Intraosseous Sacral Neurinoma
}

\author{
Dr. med. Michael Janka ${ }^{1}$, Dr. med. Adib Hajer ${ }^{2}$, Prof. Dr. Tarun Goyal ${ }^{3}$, Prof. Dr. Stefan \\ Sesselmann ${ }^{4}$, Prof. Dr. med. Alexander Schuh ${ }^{5 *}$ \\ ${ }^{1}$ Musculoskeletal Center, Neumarkt Hospital, 92318 Neumarkt, Germany \\ ${ }^{2}$ Department of Neurosurgery, Marktredwitz Hospital, 95615 Marktredwitz, Germany \\ ${ }^{3}$ Department of Orthopaedics, All India Institute of Medical Sciences, Bathinda, Bathinda, Punjab, India \\ ${ }^{4}$ Institute for Medical Technology, Ostbayerische Technische Hochschule Amberg-Weiden, Hetzenrichter Weg \\ 15, 92637, Weiden, Germany \\ ${ }^{5}$ Department of musculoskeletal research, Marktredwitz Hospital, 95615 Marktredwitz, Germany
}

*Corresponding Author: Prof. Dr. med. Alexander Schuh, Department of Musculoskeletal Research, Marktredwitz Hospital, 95615 Marktredwitz, Germany, Email: A.Schuh@Klinikum-Fichtelgebirge.de

\begin{abstract}
Schwannoma (Syn: Neurinoma) is a benign tumor that arises mainly in sensory nerve sheaths. Intraosseous lesions are rare, accounting for less than $0.2 \%$ of primary bone tumors and are located most often in the mandible and sacrum. Neurinomas are typically well-limited, encapsulated, and lobulated tumors. We report the case of a 74 year old women suffering from recurrent low back pain. An intraosseous sacral neurinoma was known for several years. Suddenly the patient developed cauda equine syndrome due to dislocation of intraosseous sacral neurinoma into the spinal canal. After resection of neurinoma neurologic deficits recovered completely within 4 months.
\end{abstract}

Keywords: Cauda equine syndrome, Dislocation, Intraosseous, Sacrum, Neurinoma

\section{INTRODUCTION}

Neurinoma (Syn. Schwannoma) is a benign neoplasm of schwann cell, arising along sensory nerve roots in the extremities and upper thorax. These tumors rarely arise within bone, among which mandible and sacrum are the most common sites of involvement $(1,2,6,7,13)$. Differential diagnosis of tumors that occur in the sacrum includes chordomas, giant cell tumors of bone or neurogenic tumor like neurilemmomas and neurofibromas, malignant neurilemmomas and neurofibrosarcomas. Some of the tumors are dumb-bell in shape; because the growth of these tumors is limited by the sacral canal, they are generally small; however, when they extend outside the sacral canal, they can bloom into huge presacral masses (12). Because most neurogenic tumors extend from inside the neural foramen to outside the spinal canal, there are characteristically few symptoms initially (12). Mobile spinal tumors are rare, and a literature search revealed only 22 reported cases that comprised schwannomas, ependymomas, neurenteric cysts, and hemangioblastoma. The majority (approximately 70\%) of the mobile spinal tumors were found to be schwannoma, and all the tumors were solid or heterogeneously solid (5). We report the case of a 74 year old women suffering from cauda equine syndrome due to a dislocated intraosseous sacral neurinoma into the spinal canal.

\section{CASE REPORT}

A 74 year old female patient suffered from recurrent low back pain for several years. MRI scan of the lumbar spine 5/2018 showed an intraosseous neurinoma of the sacral bone (fig.1). In September 2019 the patient presented to the emergency room with acute onset of low back and bilateral $\mathrm{S} 1$ paresis $4 / 5$ and urinary retention. Sign according to lasègue was positive bilaterally. Ultrasound examination of the bladder revealed $500 \mathrm{ml}$ residual urine. MRI scan of the lumbar spine showed dislocation of 
intraosseous sacral neurinoma into the spinal canal (fig.2). Hemilaminectomy and resection of the tumour was performed immediately. Histopathologic examination showed a neurinoma grade I according to WHO classification.
2 days later urinary catheter could be removed, the patient was out of any pain. One week after operation patient was sent to rehabilitation centre with persistent bilateral S1 paresis $4 / 5$. Neurologic deficits recovered completely at latest follow- up 4 months later.

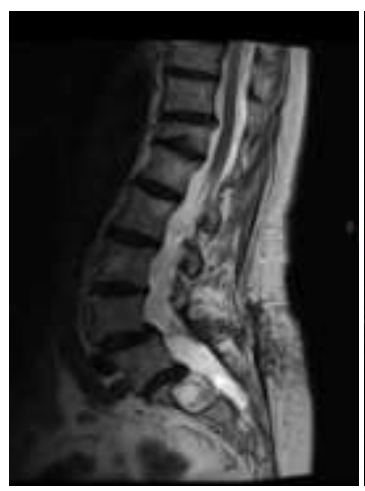

a)

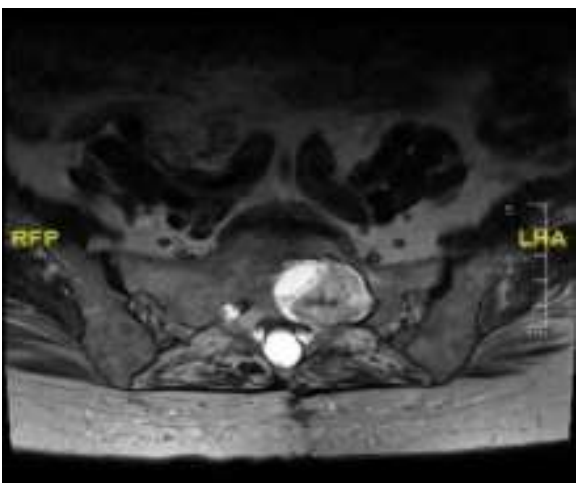

b)

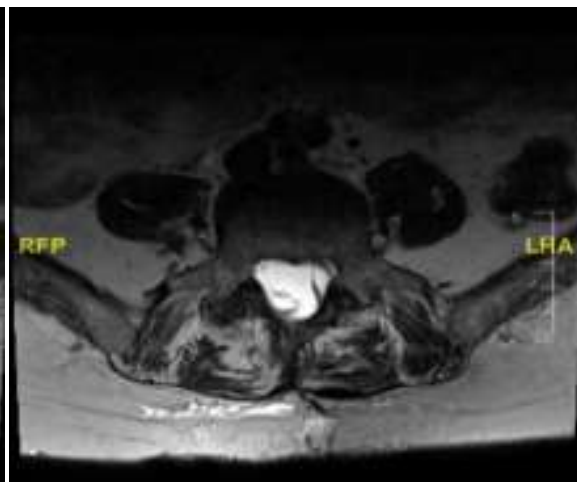

c)

Fig.1. MRI scan of the lumbar spine:

a) Sagittal and b) Axial T2-weighted MRI sequence at S1 level showing an intraosseous sacral neurinoma with mixed low signal intensity on the basis of high signal intensity. c) Axial T2-weighted MRI sequence at L5 level shows a normal spinal canal.

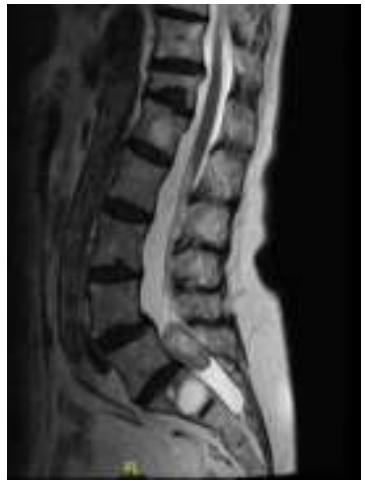

a)

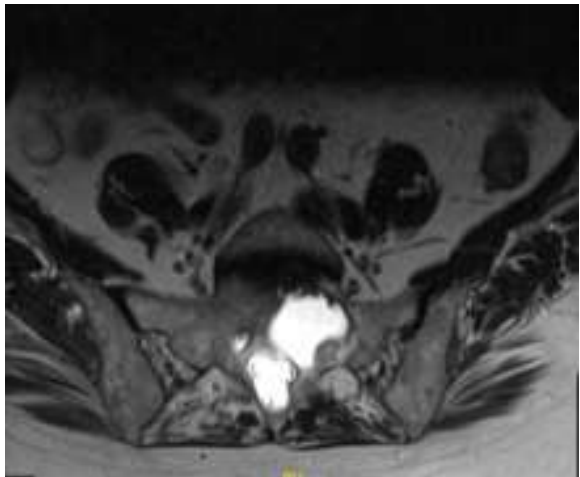

b)

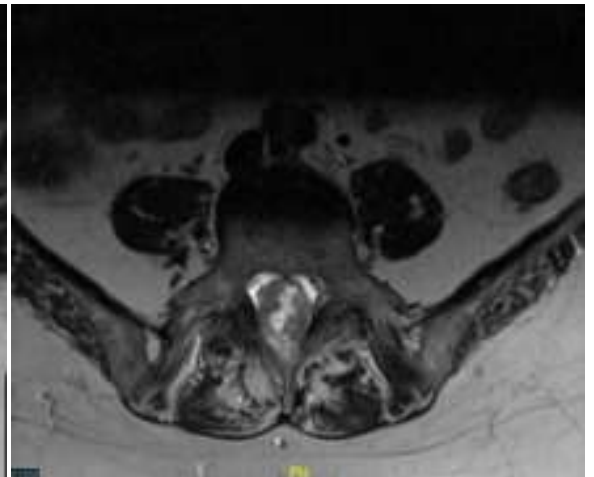

c)

Fig.2. MRI scan of the lumbar spine:

a) Sagittal and b) Axial T2-weighted MRI sequence at S1 level showing a dislocated neurinoma into the spinal canal at L5 level and cystic "empty" lesion of the sacral bone. c) Axial T2-weighted MRI sequence at L5 level shows occlusion of the spinal canal.

\section{DiSCUSSION}

Schwannoma (neurioma) is a benign tumor that arises mainly in sensory nerve sheaths (13) and seem to appear between the third and the sixth decades. The mean age of osseous neurinomas is 41.1 years (8). Clinical presentation of lumbar or sacral neurinoma is variable, from no symptoms to pain, radiculopathy, motor deficits, and cauda equina syndrome $(3,13)$. The cauda equina syndrome compresses multiple nerve roots of the sacro-lumbar area and manifests neurological symptoms such as pain in the back, the pelvis, or the lower extremities, as well as vesical dysfunction (6).
Intraosseous neurinomas are very rare and most often located in the mandible and sacrum. Other reported sites include ulna, humerus, femur, tibia, ribs, patella, scapula, maxilla, the small bones of the hands, and vertebral bodies (13).

Several theories have been proposed to explain the intraosseous component of these tumors. An extraosseous tumor that causes secondary erosion of adjacent bone, an intraosseous tumor arising within the osseous nutrient canal growing in a dumbbell-shaped configuration and causing secondary enlargement of the canal, or an intraosseous tumor originating purely within the medullary cavity of bone (11). On imaging 
and histology, it might be difficult to determine if the tumor truly arises in the osseous substance, osseous nutrient canal or is extraosseous and secondarily involves adjacent bone (10).

But intraosseous schwannoma is a curable nerve tumor. Magnetic resonance is the best indicated imaging. Typical MRI findings of schwannomas have been reported as masses of low signal intensity on T1-weighted images and high signal intensity on T2-weighted images (10). The diagnosis confirmation is histological and immunohistochemical. Total surgical removal is the gold treatment. The outcome is good in benign forms. Sacral nerve roots should be preserved as much as possible (10). Neurinomas tend to reach an enormous size and expand towards the anterior, the posterior, pelvis, or in combination due to the relative mobility of the roots and the wide diameter of the spinal canal surrounding them, which sometimes makes them usually difficult to manage (10). If the tumor is confined to the front of the sacrum, anterior approach is preferred. Otherwise, most of these tumors can be removed via posterior approach alone. Posterior approaches can also be performed to remove sacral schwannomas with large presacral component via proper fenestration. But when extraspinal portion is greater than the intraspinal a combined approach is preferred (10).

Usually neurologic deficits appear due to tumor progression and massive tumor mass with destruction of the sacrum $(1,10)$. In our case cauda syndrome developed due to dislocation of intraosseous sacral neurinoma. Mobile spinal tumors are a rare condition and have been published for schwannomas, ependymomas, neurenteric cysts, and hemangioblastoma $(5,9)$.

Previous reports have proposed possible mechanisms for the mobility of extramedullary tumors, including elongation of the nerve root due to tension resulting from the weight of the tumor, a cranial shift caused by the injection of intrathecal contrast medium during myelography, and the intentional use of a Valsalva maneuver or postural changes (5).

In our case we could not determine the mechanism of dislocation of neurinoma. To our knowledge our case is the first one, developing cauda syndrome due to dislocation of an inraosseous sacral neurinoma into the spinal canal. Immediate MRI imaging and surgical treatment is indicated to achieve good to excellent clinical results. We follow Pan et al.
(10), that total surgical removal is the gold treatment in neurinoma surgery. The outcome is good in benign forms. Sacral nerve roots should be preserved as much as possible (10).

\section{CONClusion}

Intraosseous neurinoma is a rare condition. Mobility of solid tumors should be kept in mind in patients having intraosseous tumors who suddenly develop neurologic deficits.

\section{LITERATURE}

[1] Boero G, Vinay F. A case of sacral neurinoma. Minerva Med. 1981 Nov 10;72(44):2991-5.

[2] Chandhanayingyong C, Asavamongkolkul A, Lektrakul N, Muangsomboon S. The management of sacral schwannoma: report of four cases and review of literature. Sarcoma. 2008;2008:845132. doi: 10.1155/2008/845132. PMID: 18779869; PMCID: PMC2528062.

[3] Choy W, Khanna R, Ortmeier TC, TapiaZegarra GG, Lindley TE, Smith ZA, Dahdaleh NS. Acute Presentation of Lumbar Spinal Schwannoma Due to Torsion: A Case Report. Cureus. 2016 Apr 25;8(4):e586. doi: 10.7759/cureus.586. PMID: 27226945; PMCID: PMC4876008.

[4] Dobran M, Nasi D, Della Costanza M, Formica F. Intralesional and subarachnoid bleeding of a spinal schwannoma presenting with acute cauda equina syndrome. BMJ Case Rep. 2019 Jul 12;12(7):e229251

[5] Hamabe F, Soga S, Imabayashi H, Matsunaga A, Shinmoto H. Mobile Spinal Schwannoma with a Completely Cystic Appearance. Am J Case Rep. 2019 Jun 17;20:859-863

[6] Kim HT, Gim TJ, Lee JH. Transient cauda equina syndrome related to a sacral schwannoma with cauda equine compression after a lumbar epidural block -A case report-. Korean J Anesthesiol. 2010 Dec;59 Suppl(Suppl):S222-5.

[7] Liu SY, Lin YM, Wei TS, Lin SJ, Liu CC, Chou CW. Exacerbation of symptoms of lumbar disc herniation complicated by a schwannoma: a case report. Kaohsiung J Med Sci. $2007 \quad$ Sep;23(9):480-5. doi: 10.1016/S1607-551X(08)70057-3. PMID: 17766218.

[8] Metoui L, Ajili F, Maiza M, Ben Ammar M, Gharsallah I, M'sakni I, Louzir B, Othmani S. Spinal cord compression revealing an intraosseous schwannoma. Case Rep Med. 2013;2013:913218. doi: 10.1155/2013/913218. Epub 2013 Dec 5. PMID: 24381595; PMCID: PMC3870097. 
[9] Moon K, Filis AK, Cohen AR. Mobile spinal ependymoma. J Neurosurg Pediatr. 2010 Jan;5(1):85-8. doi: 10.3171/2009.7.PEDS09244. PMID: 20043741.

[10] Pan W, Wang Z, Lin N, Huang X, Liu M, Yan $\mathrm{X}, \mathrm{Ye} Z$. Clinical features and surgical treatment of sacral schwannomas. Oncotarget. 2017 Jun 6;8(23):38061-38068.

[11] Summers S, Jose J, Barrera CM, PretellMazzini J, Subhawong T, Nguyen NV, Kerr D, Nielsen GP, Rosenberg AE. Intraosseous schwannomas involving the sacrum:
Characteristic imaging findings and review of the literature. Neuroradiol J. 2018 Oct;31(5):531-540.

[12] Sun W, Ma XJ, Zhang F, Miao WL, Wang CR, Cai ZD. Surgical Treatment of Sacral Neurogenic Tumor: A 10-year Experience with 64 Cases. Orthop Surg. 2016 May;8(2):162-70.

[13] Zhang F, Lu F, Jiang J, Wang H. Two Case Reports and an Updated Review of Spinal Intraosseous Schwannoma. J Korean Neurosurg Soc. 2015 Jun;57(6):478-83.

Citation: Michael Janka, Adib Hajer, Tarun Goyal, Stefan Sesselmann, Alexander Schuh. "Cauda Equine Syndromedue to Dislocated Intraosseous Sacral Neurinoma”. 2021; 6(2):1-4. DOI: https://doi.org/10.20431/ 2456-0588.0602001.

Copyright: (C) 2021 Authors. This is an open-access article distributed under the terms of the Creative Commons Attribution License, which permits unrestricted use, distribution, and reproduction in any medium, provided the original author and source are credited. 